\begin{tabular}{|c|c|c|c|c|c|}
\hline MUNIBE Antropologia-Arkeologia & $n^{\circ} 71$ & $257-272$ & DONOSTIA & 2020 & ISSN 1132-2217 • eISSN 2172-4555 \\
\hline
\end{tabular}

\title{
El eterno desafío de potenciar lo propio... Gentrificación y turismo de masas en la ciudad histórica. A propósito de Córdoba (Andalucía, España)
}

\author{
The eternal challenge of empowering what is yours... \\ Gentrification and mass tourism of a historical city. \\ The case of Córdoba (Andalusia, Spain)
}

PALABRAS CLAVE: Arqueología, antropología, patrimonio, turismo, etnografía.

GAKO-HITZAK: Arkeologia, antropologia, ondarea, turismoa, etnografia.

KEY WORDS: Archeology, Anthropology, Heritage, Tourism, Etnography.

Desiderio VAQUERIZO GIL ${ }^{(1)}$

José $\mathrm{M}^{\mathrm{a}}$ Manjavacas Ruiz. In memoriam

\section{RESUMEN}

Breve reflexión a partir del origen histórico-arqueológico del patio urbano, en sus diversas modalidades, con perspectiva diacrónica y particular atención a la ciudad de Córdoba. Se analizan los patios como legado patrimonial y fenómeno turístico, incidiendo en sus valores y también en las amenazas que cuestionan gravemente la fiesta homónima y los hace peligrar como valor material e inmaterial, íntimamente ligados a determinadas expresiones arquitectónicas y, más en concreto, a un concepto y una forma específicos de vida, en el marco de la ciudad histórica en abstracto. Finalmente, se incide en el papel que desempeñan como seña de identidad, factor idiosincrásico y recurso propio, invocando la responsabilidad colectiva a la hora de propiciar con urgencia el consenso entre todos los agentes implicados, a fin de buscar para ellos nuevos modelos que huyan de la instrumentalización.

\section{LABURPENA}

Hiriko patioaren jatorri historiko-arkeologikotik abiatuta egindako gogoeta laburra. Kordoba hiriari arreta berezia jarri zaio eta ikuspegi diakronikotik abiatuta egin da gogoeta. Patioak turismo-fenomeno eta ondare-legatu gisa aztertu dira, horren balioetan eta izen bereko festan eragin larria izan dezaketen eta balio material eta ez-material gisa arriskuan jar ditzakeen mehatxuetan arreta berezia jarrita. Patioak adierazpen arkitektoniko jakin batzuei hertsiki lotuta daude eta, zehatzago esanda, abstraktuan azaldutako hiri historikoaren baitan bizimodu espezifiko eta kontzeptu bati lotuta. Amaitzeko, nortasun-ezaugarri, faktore idiosinkrasiko eta baliabide propio gisa betetzen duten rola azpimarratu nahi izan da, inplikatutako eragile guztien artean adostasuna presazkotasunez errazteko garaian erantzukizun kolektiboa eskatuta. Horren helburua da haientzat instrumentalizaziotik aldentzen diren eredu berriak bilatzea.

\begin{abstract}
Historical cities are living archaeological sites in a continual process of development. They are palimpsests that ultimately become unique units marked by eclectic albeit unique personalities stemming from centuries of syncretism of processes of abstraction and syntheses that end up yielding individual signs of identity, exclusive cultural profiles and extraordinary collections of heritage. This is the case of Córdoba, one of the most complex and extensive archaeological sites (in both space and time) of the world with an occupation spanning 5,000 years. It was a reference as the capital of Baetica, the main Roman province of the West, and later, between the 8th and 12th centuries, as the capital of Al-Andalus. It even served during the 10th century as the seat of the great Western Umayyad Caliphate. It was a melting pot fusing its own traditions with foreign influences yielding a unique blend with a particular architectural feature, the domestic patio, playing a predominant role.

The current study offers a brief review of Córdoba's inner patios, from their simple beginnings to the stately patios that today make up an urban landscape recognised universally by its annual patio festival, a celebration classified as an Intangible Heritage of Humanity. However, like many other historic cities, Córdoba of late has fallen into the pitfalls of mass tourism, seriously questioning and threatening its carrying capacity. Always at the service of an overflow of tourism, its historic centre, also classified as a World Heritage Site, has initiated a wild process of gentrification that could lead to a significant breakdown of its natural evolution. Every urban complex has to evolve. Yet the historical centre, so admired by masses of tourists, has been shaped day by day by its original residents. Is their continued expulsion, as is occurring in many of its areas, not a sign that the city centre is being remodelled into a sort of fake decor?
\end{abstract}

\footnotetext{
(1) Universidad de Córdoba. aa1vagid@uco.es
} 
These are very profound issues that require calm and careful reflection, especially during the current health crisis that has provoked a traumatic suspension of tourism leaving the city's streets and patios empty and businesses in a precarious state. It is now a time for self-criticism, to etymologically take advantage of the meaning of the word "crisis" and turn it into an opportunity to pinpoint errors of the past. It is a moment to reorient the model in a way to protect its signs of identity - its common heritage - without complexes and put an end to the almost total dependence on the tertiary sector so as to diversify the economic fabric, optimise its efforts by creating structure, and prepare for a future based on a consensus without renouncing what grants Córdoba its unique character, its marked idiosyncrasy and its centuries-long essence. If patrimony is ultimately a matter of values, then perhaps everything occurs to enhance heritage, sublimating it without adulterating it. This is a difficult but peremptory and absolutely necessary task. Otherwise, the patio festival might become completely alien to itself.

\section{BREVES NOTAS HISTÓRICAS}

Por razones obvias, el patio como elemento arquitectónico está directamente unido a ese crisol de culturas que se han desarrollado desde antiguo en torno al Mare Nostrum, favorecidas por el clima, el medio y la historia común. Las buenas temperaturas que se suelen disfrutar la mayor parte del año, matizadas en los momentos más rigurosos del mismo por vegetación, porches y agua; las posibilidades que el patio ofrece para distribución del espacio doméstico, ventilación, vida en familia, representación social, trabajo, descanso, meditación, ocio o simple contemplación; su carácter de eje estructurador de la casa, versátil, polivalente e incluso múltiple según los casos, explican por sí mismos el puesto privilegiado que tales soluciones han ocupado en el marco de la arquitectura doméstica mediterránea, entendida la vivienda como lugar estricto de hábitat y con independencia de su época, su tamaño o sus pretensiones.

Los pueblos del arco mediterráneo ligan cualquier celebración -individual, colectiva, conmemorativa, festiva, ritual o religiosa- al buen comer, el buen beber y el disfrute conjunto de los otros y de la naturaleza. Más allá de cuestiones puramente sociales o socializadoras, familiares o locales (como combatir el calor, ventilar la casa o nutrirla de agua a través del pozo), lo importante es transcurrir la vida al aire libre; el contacto directo con cielo y tierra; el carácter aglutinador o de retiro, según el caso, que ofrecen ámbitos diseñados explícitamente para ello; su valor como factores de saneamiento y profilaxis; su posición privilegiada para una comunión directa con los dioses protectores de la casa y de la naturaleza, o la ambientación evocadora del paraíso que implican, convertidos en un adelanto del mismo en la tierra ${ }^{1}$.

Para rastrear el origen del patio hemos de acudir, cuando menos, a los primeros palacios mesopotámicos, donde fueron elemento determinante en su organización interna para la distribución de funciones y la canalización de los visitantes que atestaban a diario sus estancias. Del Próximo Oriente pasan a las culturas minoica y micénica; y después a la griega, la etrusca, la ibérica ${ }^{2}$ y la romana. En la Roma de época imperial hubo dos tipos básicos de vivienda: la insula o casa de vecindad, en realidad un bloque de apartamentos con servicios comunes organizados en torno a uno o más patios, y la domus, casa unifamiliar de una sola planta que adapta viejas fórmulas helenísticas y utiliza como elementos umbilicales atrio y peristilo.

Al atrio, cuyos tejados mandaban el agua de la lluvia a una cisterna situada bajo él (impluvium), se accedía directamente desde la calle, y tuvo siempre un cierto componente público: en él recibía el patronus a sus clientes para la salutatio matutina, entregándoles como contrapartida la sportula o donativo diario; en él se organizaban los velatorios -los cadáveres con los pies hacia la puerta en claro signo de exclusión- y se exponían las máscaras de los antepasados. Por el contrario, el peristilo, amplio patio interior dotado de juegos de agua, vegetación, mosaicos y esculturas, que a veces contaba con acceso directo a través de una entrada lateral, se destinaba a la vida familiar, al disfrute cotidiano y al ejercicio bien planificado de la vanidad: a él solían abrir las habitaciones principales de la casa, incluidos los comedores y salas de representación para fiestas y banquetes; en él se leía poesía, se declamaba a los clásicos, y también se intrigaba (vid. por ejemplo Gros, Torelli 2007, o Jashemski et al. 2017).

Algunos de las domus de atrio y peristilo mejor conservadas del Imperio pueden visitarse en Pompeya (Zanker, 1998; Flora 2015). En Córdoba, sin embargo, sólo las tenemos por el momento de peristilo, tal vez porque en ningún caso se han documentado completas, o porque progresivamente los atrios perdieron funcionalidad (Neira Jiménez, 2018, a y b; o Vaquerizo, 2018b) (Fig. 1). Todas ellas hablan de ambientes domésticos marcados por el lujo y una estricta fidelidad a los parámetros culturales de Roma y el mundo helenístico. De las insulae cordubenses no tenemos la menor noticia, pero es de suponer que, como en otras grandes

\footnotetext{
1 Son todos ellos aspectos que se han visto sublimados durante la crisis sanitaria provocada por el Covid19 y los encierros domiciliarios que ha acarreado, muy diferentes de sobrellevar en función de que la casa en la que debían transcurrir tuviera o no patio propio.

2 Los poblados de época ibérica o turdetana no son bien conocidos en Andalucía. Entre los pocos excavados se encuentran casas sin patio, como en el Cerro de la Cruz (Almedinilla, Córdoba) (Vaquerizo et al., 1994), y casas con patio, como las detectadas en Puente Tablas (Jaén) (Ruiz Rodríguez et al. 2015), si bien en unos y otros muchas actividades cotidianas se realizaban fuera de la casa sensu stricto. En cualquier caso simplifico absolutamente, por cuanto sería posible distinguir estructuras domésticas con algún tipo de patio en otras muchas culturas hispanas previas a la llegada de Roma, entre ellas las orientales u orientalizantes (piénsese por ejemplo en el santuario de El Carambolo; al respecto, vid. algunos de los trabajos contenidos en De la Bandera, Ferrer 2016).
} 


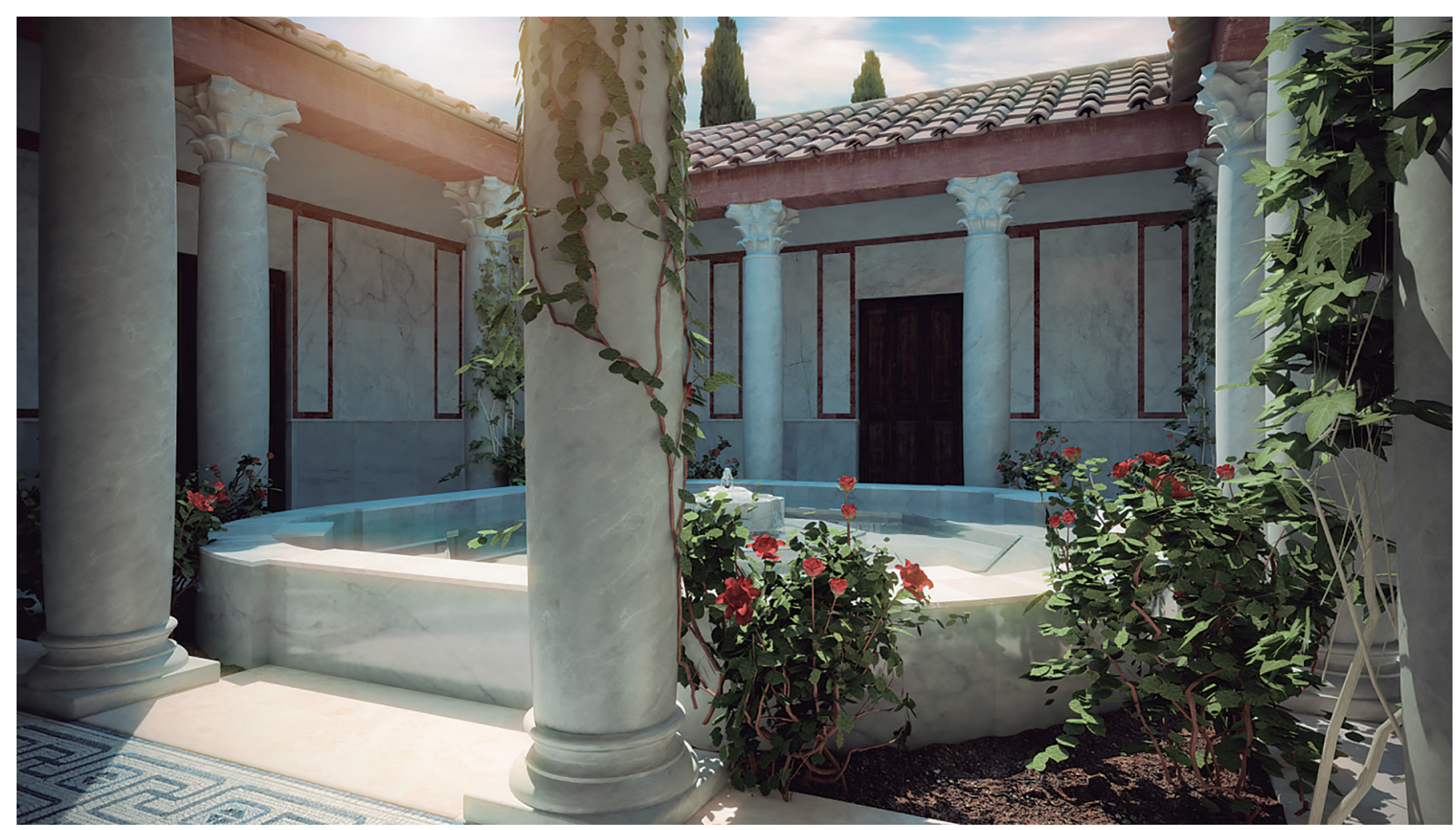

Fig.1. Recreación del peristilo documentado en la denominada "Villa romana de Santa Rosa (Córdoba) (Arqueonova; cortesía J.M. Salinas). / Reconstruction of the peristyle of the Roman"Santa Rosa Villa" (Córdoba) (Image Arqueonova; courtesy of J.M. Salinas).

ciudades del Imperio (Ostia Antica es paradigmática al respecto), convivirían grandes mansiones unifamiliares con bloques de apartamentos y casas de vecinos, en una dualidad con mil pasos intermedios y todo tipo de mixtificaciones que ha llegado incluso a nuestros días.

Tales principios rectores fueron también trasladados al campo, en forma de asentamientos que reproducen el esquema de las grandes mansiones urbanas (urbs in rure), al servicio del boato, la ostentación, el aislamiento pretendido y, por supuesto, el disfrute del otium. En las provincias hispanas no contamos hasta el momento con villae de recreo en sentido estricto, que sí menudean en Italia, particularmente en el Golfo de Nápoles (Rossi, 2002). Tales villae evolucionan a la vez que el Imperio hasta alcanzar sus expresiones más conspicuas entre finales del siglo III y mediados del $\mathrm{V}^{3}$, con zonas residenciales que destacan tanto por sus esquemas constructivos como por sus programas ornamentales, acompañados en ocasiones de artificios capaces de epatar a propios y extraños; siempre, en contextos paisajísticos privilegiados y en torno a patios que recrean de forma magistral la idea de paradéisos.

Este paisaje urbano, arquitectónico y humano se ve gravemente afectado por el final del Imperio, que transforma el mundo conocido en beneficio de nuevas fórmulas de poder, nuevos periodos de inestabilidad, nuevos aportes poblacionales y el triunfo del Cristianismo (Ruiz Bueno, 2018; Sánchez Ramos y Mateos, 2018). En este proceso, las casas experimentan cambios de enorme trascendencia. Sobre las viviendas de los sectores más bajos de la población seguimos sin tener demasiadas noticias, más allá de que muchas de ellas, poco más que cabañas, ocupan el interior de los grandes edificios de espectáculos romanos: teatros, circos y anfiteatros, fosilizados algunos de ellos en el callejero actual de ciudades históricas como Roma, Firenze, Lucca o Valencia. En Córdoba, el anfiteatro condicionó la planta del arrabal islámico asentado siglos más tarde sobre sus ruinas (Vaquerizo y Murillo, 2010) (Fig. 2).

También las domus pierden su valor unifamiliar para ser ocupadas por grupos gentilicios diversos que aglutinan en ellas viviendas, lugares de trabajo, talleres y a veces incluso establos, llegando a convivir con los animales. Asistimos así a una importante solución de continuidad con el mundo clásico que, sin embargo, de forma un tanto paradójica, repararán pocos siglos más tarde los árabes. Cuando llegan a Córdoba el modelo habitacional que encuentran es el tardoantiguo, sostenido por elites cristianas de procedencia en muchos casos centroeuropeas. Ellos rescatan de forma activa el legado de Roma, haciendo confluir la tradición orien-

3 Vid. los trabajos contenidos en Hidalgo 2016. 


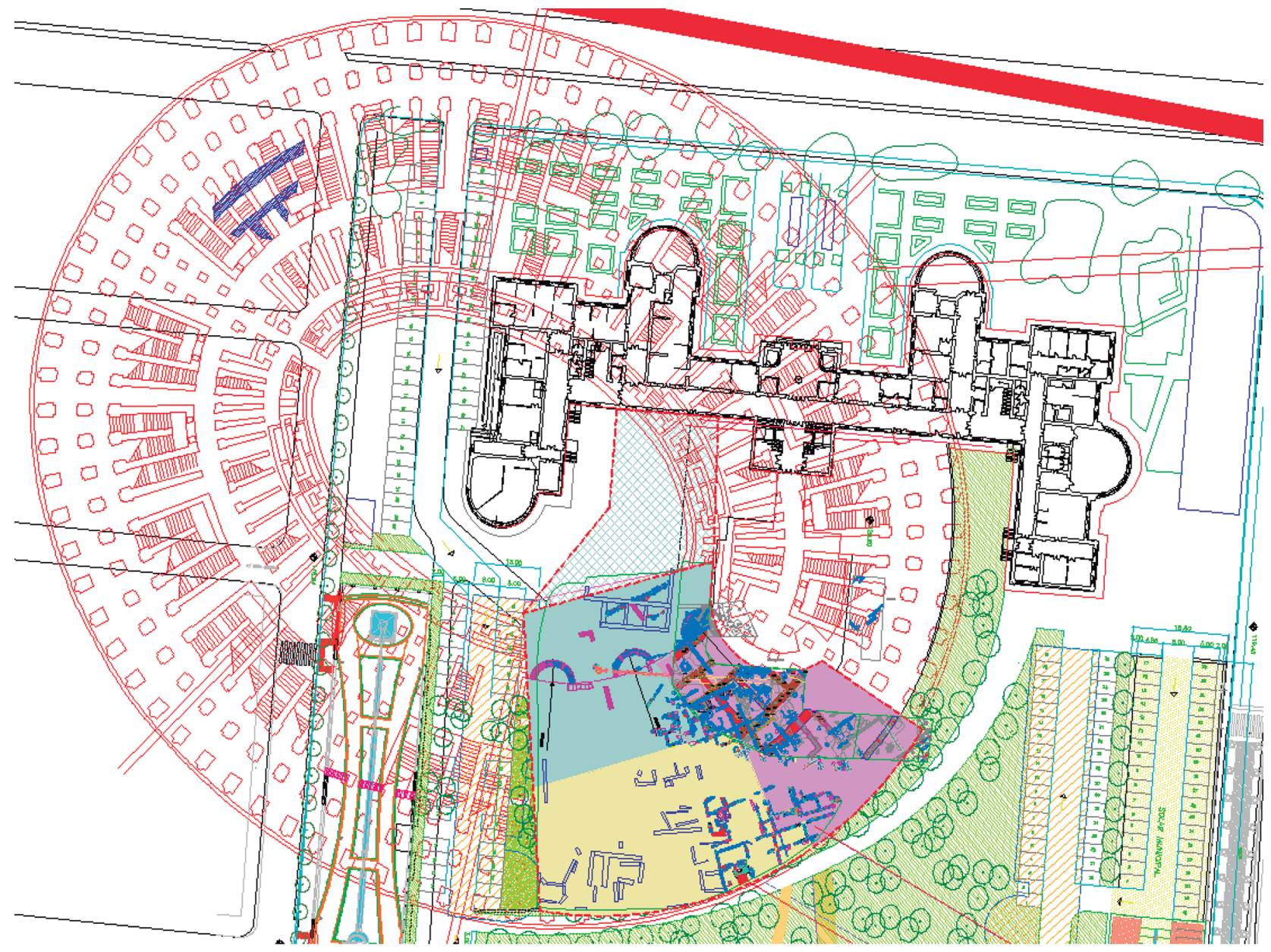

Fig.2. Planta del anfiteatro cordubense, en la que se puede observar cómo en su parte meridional las estructuras fueron reutilizadas (y fosilizadas) por un arrabal islámico (Imagen Convenio GMU-UCO). / Plan of Córdoba's Roman amphitheater. Its southern features are conserved due to their reuse in Islamic times (Image GMU-UCO collaboration).

tal del palacio omeya, materializada en Córdoba en forma de grandes palacios y almunias, y de la casa grecorromana (incluidas las insulae), organizadas siempre en torno a uno o varios patios.

Entre las primeras, destaca por sólo poner un ejemplo la que Abderramán I se mandó construir en La Arruzafa. Por el momento sigue sin poder ser excavada, pero ha bastado la geofísica para saber que se trató de una adaptación casi literal del palacio que su abuelo Hisam disfrutó en al-Rusafa, antigua Sergiopolis, en Siria (González Gutiérrez, 2018, 312 ss., Fig. 6, con bibliografía anterior); el escenario de sus juegos de niño y su formación como hombre. Abderramán I lo reproduce en Córdoba como factor de legitimación dinástica, acompañándolo de huertos y jardines que le sirven para aclimatar numerosas especies; y lo hace sobre una antigua villa romana (Clapés, Rubio, Castillo 2019). De estos momentos iniciales del Emirato apenas conocemos las claves de su arquitectura doméstica en Córdoba, pero resultan muy significativas las excavaciones practicadas a principios de los años dos mil en el viejo arrabal de Saqundah; barrio populoso ubicado al otro lado del río (se conoció de hecho como arrabal meridional, al rabad al-yanubi), cuyos habitantes, fundamentalmente comerciantes, artesanos y gente de condición humilde, se levantaron en 818 contra los abusos fiscales de emir al Hakam I, desapareciendo casi en el envite: el enclave por arrasamiento, y sus vecinos por deportación (García Gómez, 1976).

De Saqundah se habían conservado, pues, los ecos histórico-legendarios, pero nada más, hasta que las excavaciones desarrolladas allí a principios de siglo (Casal, 2020) pusieron al descubierto los cimientos de un amplísimo sector del arrabal (16.000 m²) (Fig. 3), conformado por estructuras domésticas, comerciales e industriales organizadas en torno a calles de hasta seis metros de anchura, con técnicas constructivas, tipologías y servicios muy diferentes a los que más tarde nutrirían los grandes arrabales califales. En estos momentos aún no existía en Córdoba la casa-patio, que como tal se desarrollará específicamente a partir cuando menos de la época califal, pero el esquema repetido 


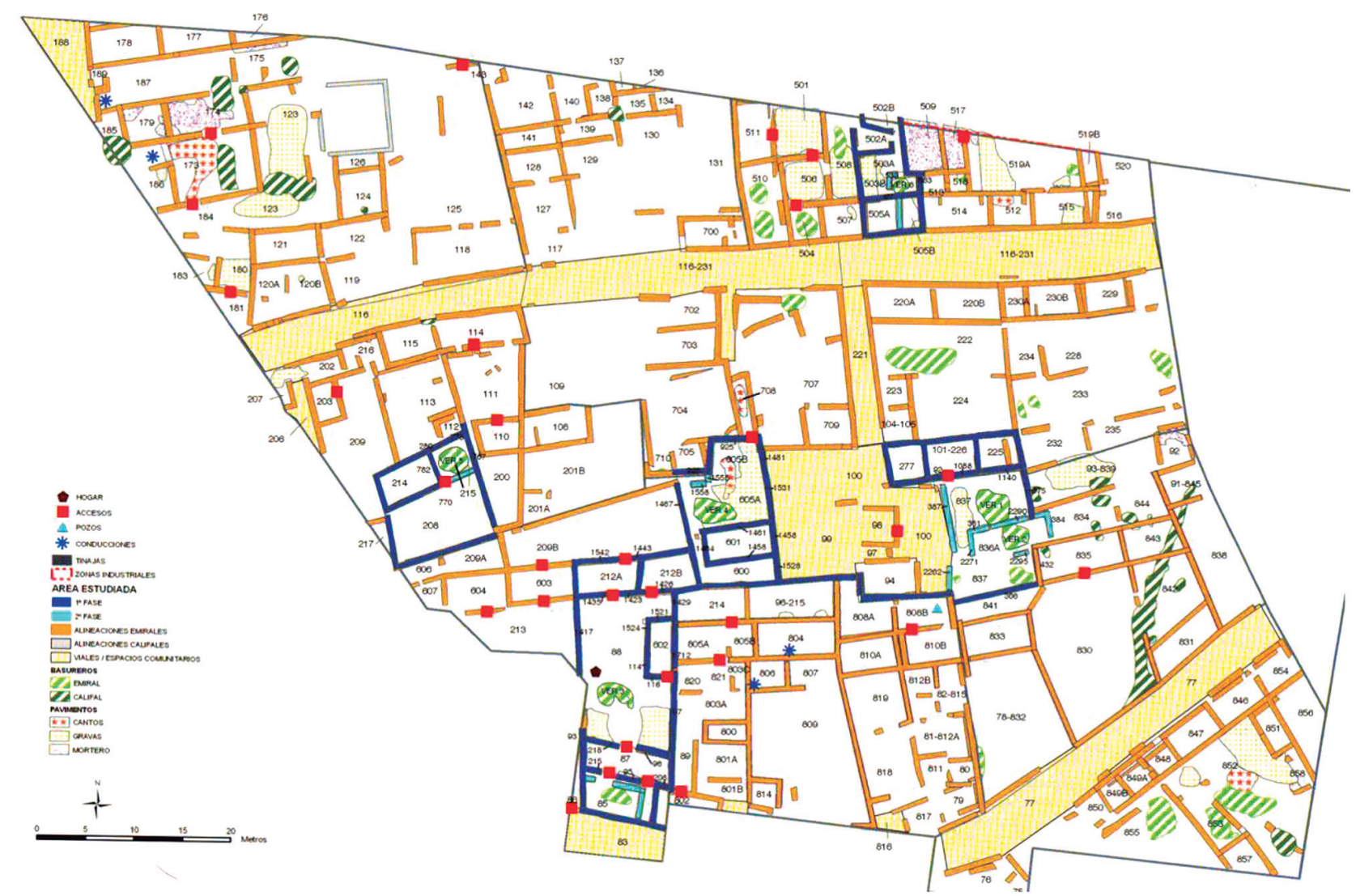

Fig.3. Arrabal de Saqundah, conformado básicamente por estructuras domésticas, comerciales e industriales. Planta de las excavaciones (cortesía M.T. Casal). / Suburb of Saqundah which basically comprises domestic, commercial and industrial features. Plan of the excavations (courtesy of M.T. Casal).

de varias casas abiertas a un espacio común evoca ya en alguna medida el de la casa de vecinos que siglos más tarde acabaría materializando en Córdoba a través de multitud de variables, capitalizadoras sin duda de influencias muy diversas.

Ya en época califal, el patio como elemento nuclear de la vivienda trasciende de nuevo las murallas y pasa a ser principio rector de los miles de casas que pueblan los nuevos arrabales, de trazado urbanístico sorprendente y alcance inimaginable hasta hace sólo unos años. Han sido muchas las excavaciones practicadas en las últimas décadas, y decenas de hectáreas las puestas al descubierto de estos barrios extramuros, diseñados conforme a criterios ortodámicos, y dotados de todo tipo de servicios, incluidos sus propios cementerios. Por desgracia, la publicación de resultados no ha ido ni con mucho pareja al movimiento de tierras (León Muñoz, 2019), y ha tenido que ser la Universidad la que se faje en la recuperación de datos y la exégesis.
Más allá de algunos trabajos de alcance nacional sobre el tema (Gutiérrez Lloret, 2021), destacan para el caso de Córdoba los más recientes y locales sobre el papel urbanizador de las mezquitas de barrio (González, 2018); el rol ejercido en la urbanización extramuros por el agua (Vázquez, 2018), o la vivienda durante la etapa almohade posterior (Blanco, 2018) (Fig. 4). Este último autor ha desarrollado un cuerpo crítico en torno a la casa-patio que demuestra hasta qué punto éste se convirtió durante la época islámica en corazón de la casa, espacio privilegiado para el descanso, el ocio y la vida íntima y familiar ${ }^{4}$, paraíso en la tierra y lugar de belleza particular potenciada por la presencia determinante del agua y de numerosas especies vegetales que la arqueología nos ha regateado debido a la metodología más que limitada de la mayor parte de intervenciones realizadas ${ }^{5}$, pero que conocemos por las fuentes escritas, evocadoras siempre de tales ambientes como bálsamo necesario para el alma y deleite insustituible para los sentidos.

\footnotetext{
4 "Por eso nada es más ajeno a la Córdoba islámica que los patios actuales de la ciudad, que se exhiben sin recelo a cualquiera que pase, como mujeres demasiado seguras de su belleza. El interior de la casa musulmana era un lugar inaccesible para la mirada de un extraño" (Muñoz Molina, 2009, 86).

5 Las aportaciones de la Paleobotánica en este sentido son fundamentales. Sin embargo, poco puede hacer esta ciencia cuando no se cuenta con muestras, ni los arqueólogos responsables de las intervenciones se han ocupado habitualmente de esta cuestión.
} 

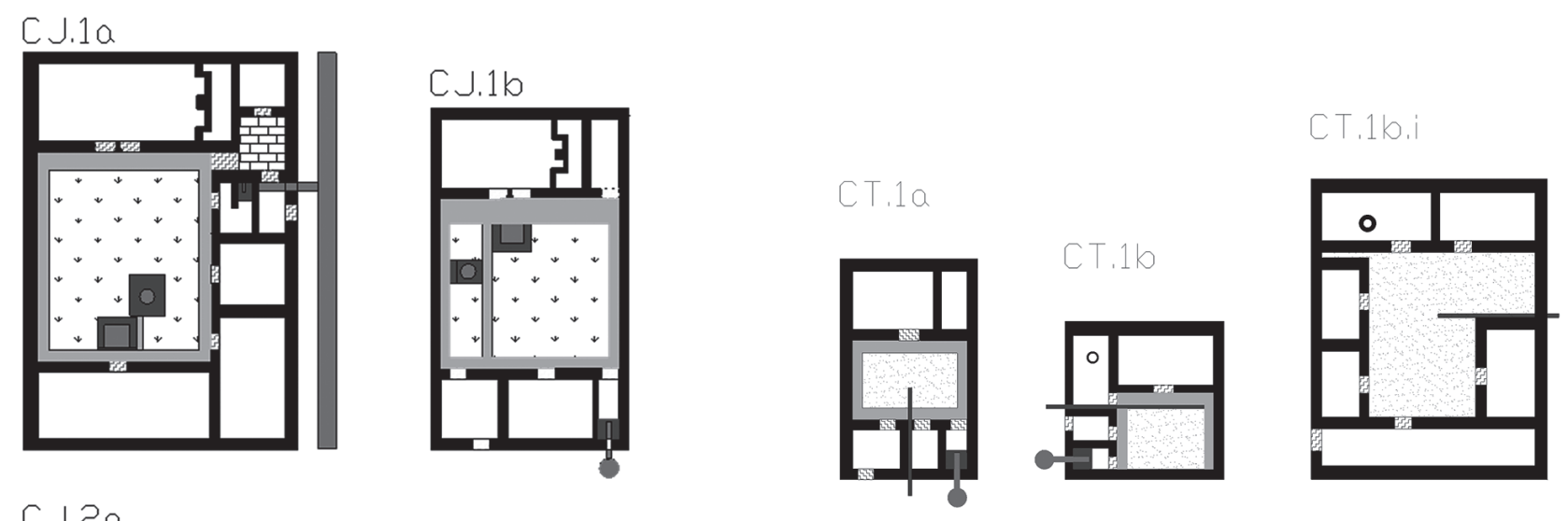

\section{J.2a}
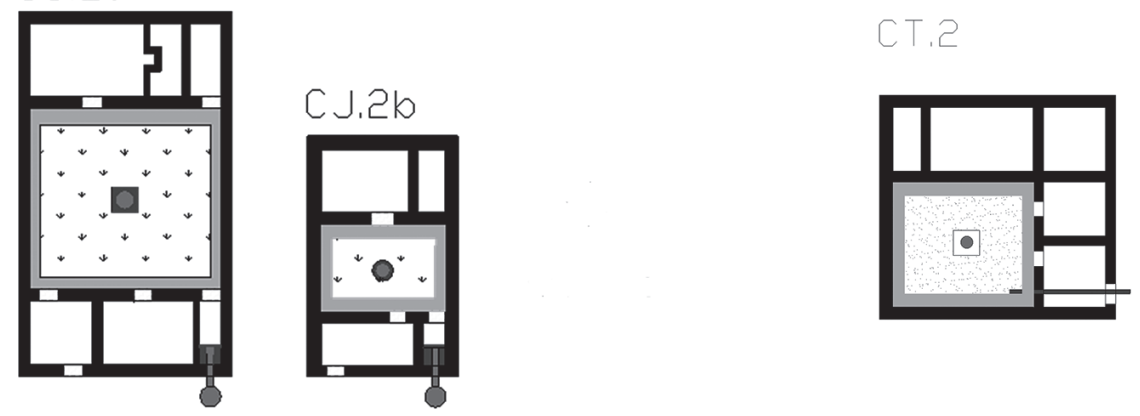

Fig.4. Tipología de viviendas con patio en la Córdoba almohade. Casas-jardín (CJ) y Casas-taller (CT) (cortesía R. Blanco). / Typology of the Almohad patio dwellings in Córdoba. Garden-houses (CJ) and workshop-houses (CT) (courtesy R. Blanco).

Finalmente, no debemos olvidar que en el siglo $X$ Qurtuba alumbra una ciudad nueva, a través de la cual lega al mundo toda una lección de urbanismo, planificación, infraestructuras y saber vivir. Hablo de Medina Azahara, que hizo del patio el elemento rector de su urbanismo, a la manera importada de Oriente (Vallejo, 2010). Abd el-Rahman III supo construir un escenario palatino a la altura de su idea de poder, desde el que irradió pensamiento, civilización y progreso, y exportó ideas, científicos y creadores. Como despoblado nunca conoció ocupación posterior, lo que redobla su vaIor. El modelo sería imitado poco después por Almanzor en Madinat al-Zahira, pero en este caso el conjunto sigue sin ser localizado.

La presencia islámica en al-Andalus se prolonga durante siete siglos largos, por lo que analizar con detalle cómo evoluciona el patio en cada una de las etapas exigiría de análisis más exhaustivos que éste. Eso, sin tener en cuenta la dimensión espacial. Al-Andalus es realidad cambiante, en el tiempo y en el espacio, y también multiétnica, por cuanto a los árabes llegados de Oriente se suman norteafricanos, muladíes y mozárabes, judíos y otras muchas razas, esclavizadas o no. De ahí que cualquier manifestación de su cultura deje casi siempre traslucir un componente mestizo que está en la base del mundo andalusí como uno de sus signos más definitorios e idiosincrásicos. Por eso, pretender para el patio en Córdoba un origen único y unívoco sería un grave error de apreciación que podría conducir a simplificaciones excesivas. En lugares tan mixtificados como la península lbérica resulta complicado buscar la "pureza de sangre" en ninguna de sus manifestaciones culturales. Somos un país de síntesis.

Sirva esta pequeña digresión para recordar que tras la conquista cristiana, que en Córdoba tiene lugar en 1236, las cosas variarán de nuevo mucho (Escobar, 1989), si bien a mi juicio las bases estaban ya puestas y el proceso será imparable hasta desembocar en el siglo XX en dos tipologías básicas de patios: los populares, casi siempre en casas de vecinos que hacen de ellos el punto neurálgico de la vida en vecindad (con sus ventajas y sus inconvenientes), y el patio señorial, que adopta un número variable y multitud de modalidades según el tipo de vivienda y los "posibles" de sus propietarios, pero que incorporan siempre un componente importante de representación, disfrute familiar, cultura y amor por la belleza (Ramos Gil, 2016). Con tales precedentes, es fácil entender la realidad actual, que ha acabado por tomar forma en la declaración de los patios cordobeses Patrimonio Inmaterial de la Humanidad.

\section{UNA MIRADA(TRISTE) DESDE LAARQUEOLOGÍA}

Córdoba es por definición una ciudad sobria, a la que le sobran "adornos" y le falta aprender a gestionar el yacimiento sin límites que representa su historia acumulada, a conservarlo, engrandecerlo y transmitirlo sin renunciar a los principios fundamentales que lo de- 
finen. Por más que el desembarco del patrimonio en el negocio turístico (o a la inversa) implique siempre renuncias, hay determinadas cosas que a mi entender son irrenunciables. Tras cinco mil años de historia ininterrumpida, la ciudad es genuina y ha de aprender con urgencia a rentabilizar recursos, a aunar esfuerzos, a crear estructura.

Córdoba constituye en sí misma uno de los yacimientos arqueológicos más completos y ricos del Occidente mediterráneo, que a su interés puramente histórico une su condición de ciudad viva. Dicha circunstancia ha provocado en las últimas décadas problemas enormes de gestión, además de difícilmente justificables sacrificios a causa de cientos de intervenciones arqueológicas por desgracia no siempre ejemplares desde el punto de vista metodológico, y mucho menos científico. Por su dilatada historia y sus características como yacimiento urbano, de extensión, potencia y complejidad inusuales, y por más que alguno de dichos aspectos pueda ser matizable según el momento, Córdoba ciudad representa un ejemplo arquetípico de todos los males que han aquejado a la arqueología andaluza desde que tuvo lugar la transferencia de competencias en materia de patrimonio desde el Gobierno central a la Junta de Andalucía y, casi enseguida, el inicio del pelotazo: enfrentamientos sostenidos entre las Administraciones responsables del patrimonio, casi sin excepción de diferente signo político; indefinición en cuanto a los requisitos exigibles para ejercer la profesión de Arqueólogo; ausencia de un proyecto sistemático de ciudad; caos metodológico; escasa cualificación de los profesionales actuantes; descoordinación entre los diversos agentes implicados; rigor insuficiente en los proyectos, las intervenciones y las memorias de excavación; laxitud en los controles oficiales; discrecionalidad en las decisiones; destrucciones masivas, etc. (Vaquerizo, 2018a).

Hace sólo unos años, la peculiar problemática del patrimonio arqueológico cordobés protagonizó un Trabajo Fin de Máster en la Universidad Complutense de Madrid (Fernández Gallardo, 2015)6 cuya autora se preguntaba en qué medida acontecimientos importantes y recientes en relación con la ciudad histórica -más concretamente, su declaración como Patrimonio de la Humanidad en 1994- podían o no haber influido en la gestión y difusión científica del conjunto. Analizaba para ello un periodo de dieciocho años, comprendidos entre 1995 y 2012, durante los cuales tuvieron lugar 80 intervenciones arqueológicas en la zona declarada Pa- trimonio de la Humanidad, frente a 635 en el resto de la ciudad. Pues bien, de todas ellas sólo se habrían dado a conocer el $27,5 \%$ en el primer caso, y el $19,13 \%$ en el segundo, lo que parece confirmar una mayor atención a las primeras (poco más del 8\%).

Sin que pueda pararme ahora a valorar la mayor o menor exhaustividad de los datos ${ }^{7}$, queda en evidencia, de entrada, uno de los problemas más graves que afectan a la arqueología cordobesa: la falta de correspondencia entre los trabajos de campo y la publicación de la información obtenida, entre la gestión y la investigación, entre la techné y la epistemé, entre lo instrumental y lo heurístico (no hablo ahora de la puesta en valor ${ }^{8}$ ni de la optimización de recursos). Han sido décadas de vorágine excavadora, en los que se ha destripado buena parte del gran yacimiento cordobés sin que la exhumación de archivos, la recuperación de material, el rigor en los datos, la interpretación histórica, la conservación e integración de los restos, la planificación, y, mucho menos, la musealización o la incorporación del escaso tejido patrimonial no arrasado en el discurso turístico y socio-económico de la ciudad hayan corrido paralelas. Así las cosas, es fácil entender que la percepción de la arqueología en Córdoba siga revistiendo tintes negativos ${ }^{9}$, sin que la labor de difusión que diversos agentes -entre los cuales destaca por méritos propios el proyecto Arqueología somos todos ${ }^{10}$ - venimos realizando contra viento y marea, haya dado todavía los resultados que cabría esperar, o serían deseables.

En síntesis, hablo de una ciudad paradigmática en lo que se refiere a la pérdida de sus archivos del suelo desde la puesta en marcha del llamado Modelo Andaluz de Arqueología; donde la Arqueología Urbana ha generado mucha más información que conocimiento histórico (Rodríguez Temiño, 2004; Salvatierra, 2013), y que tres décadas largas después sigue sin contar con un discurso patrimonial propio. Un contexto un tanto apocalíptico en el que no se salva nadie: no lo hacen el Estado ni las Administraciones públicas, incapaces de aplicar en su plena dimensión la normativa legal, reconociendo de paso el carácter de ciencia de la Arqueología; tampoco la Universidad, cómplice en ocasiones de un laissez faire que se encuentra en la base de grandes desastres arqueológicos -su misión principal es investigar, formar y generar pensamiento, sí, pero también actitud crítica, imbricación con el entorno, activismo social y compromiso-; y, por supuesto, menos que nadie los propios profesionales (libres, comerciales, o como se

\footnotetext{
${ }^{6}$ Gracias a su directora, Alicia Castillo Mena, por facilitarme el acceso al mismo.

7 Posiblemente muy limitados, dada las características de la recogida (sólo internet), y el carácter ajeno por completo a la arqueología de la autora. 8 Y "el consecuente conflicto dialéctico que ella genera, que lleva a la ciudad a reivindicar su importante pasado milenario como seña de identidad y distintivo y, a la vez, a borrar de su fisonomía moderna la huella arqueológica de tal pasado" (Fuertes e Hidalgo, 2005, 31).

${ }^{9}$ Cómo percibe la arqueología la sociedad cordobesa, en positivo y en negativo, habrá de ser, antes o después, objeto de un estudio monográfico similar al realizado recientemente (2015) para el País Valenciano. Hablo de la Tesis Doctoral (inédita) Iberos, públicos y cultura de masas. El pasado ibérico en el imaginario colectivo valenciano, de A. Vizcaino Esteban (cfr. Vizcaíno 2015, 199 ss.).

${ }^{10}$ www.arqueocordoba.com
} 
quiera llamarlos), atrapados en una dinámica vertiginosa en la que el trabajo de campo le ganó desde el primer minuto y por goleada la partida a la investigación, prácticamente nula, a pesar de los informes publicados en el Anuario Arqueológico de Andalucía, donde se recoge, sin rubor, criterio, o fondo científico alguno, más de un desatino difícilmente justificable ${ }^{11}$.

Aun cuando queda por valorar en su plena dimensión el volumen proporcionalmente más importante de los datos recuperados, todos estos trabajos han incrementado de forma exponencial nuestro conocimiento sobre el pasado de la ciudad, al tiempo que han supuesto pérdidas gravísimas y sin precedentes, de información histórica y de recursos. Urge, pues, hacer balance, aprender de los errores, actuar en consecuencia y no transmitir por más tiempo a la población una imagen negativa de la arqueología, insistiendo en su carácter de ciencia histórica y social, capaz de generar información, pero también nuevos activos patrimoniales. Y el arma principal para luchar contra el rechazo de la sociedad es la educación, clave para que asuma, respete y defienda como propios los testimonios materiales de su pasado (Vaquerizo, 2018a).

Es preciso conservar con criterio, señalizar de manera rigurosa, uniforme, global e innovadora, potenciar sin reservas el uso de las nuevas tecnologías, facilitar el acceso físico o virtual a los restos (Grande León 2016), crear rutas temáticas y cronológicas que permitan ofrecer a la ciudadanía un discurso diacrónico, coherente y completo sobre el gran conjunto arqueológico cordubense, una herramienta educativa y turística de primer orden que, sin duda, enriquecería de forma importante su oferta patrimonial. De lo contrario, tales integraciones acaban provocando el efecto contrario, lanzan a la sociedad un mensaje de abandono, peso muerto y falta de utilidad que da la razón a los detractores de la arqueología.

Tras años de excavaciones desaforadas, es tiempo de estudio, imprescindible para incrementar nuestro conocimiento sobre la ciudad antigua y su evolución en el tiempo, pero también de aprovechar cultural y turísticamente lo poco que hemos dejado (Moya, 2010, 23). Por más que cueste percibirlo, Córdoba es mucho más que el templo romano, Medina Azahara o la Mezquita, que debería ser entendida como un reclamo, no como un fin en sí misma.

Conviene para ello olvidar las polémicas estériles, mirar a la historia, reintegrar a la ciudad su integridad patrimonial y su esencia; y, de paso, si es posible, generar tejido económico y empresarial para seguir viviendo en, para, por y de ella. Los tiempos de crisis feroz como los que atravesamos -económica, sanitaria y de valores- han de ser aprovechados como oportu- nidad irrepetible para la reflexión y la autocrítica, que sirvan para revisar el modelo. También, para combatir la desesperanza y la falta de perspectivas con ideas, iniciativas y cultura emprendedora; siempre, huelga decirlo, desde el rigor, la solvencia, el consenso, la imaginación, la innovación y la generosidad, bases imprescindibles de cualquier acción conjunta.

\section{LOS PROBLEMAS DE UNA CIUDAD DESORIENTADA}

Mayo es el mes cordobés por excelencia. La ciudad ha hecho de él su tarjeta más internacional de presentación ante el mundo, amplificada desde 2012 con la declaración de los patios como patrimonio inmaterial de la Humanidad por la Unesco. Forma parte de su apuesta, cuando menos discutible, por el folklore y el turismo de masas o aluvión, por su imagen más evidente y festiva -la cultura del disfrute, se ha dado en llamar-, en perjuicio de otras claves definitorias de su naturaleza a las que sigue dando la espalda con criterios excluyentes.

"Córdoba es ahora una ciudad desorientada y en brazos de las modas... Ya no es Córdoba, es un reflejo no de lo que fue, sino de otra Andalucía, de otro aire... Tengo la esperanza de que el futuro de Córdoba sea... una ciudad cultural... La cultura es lo único que puede salvar a Córdoba". Son palabras del Príncipe de Asturias de las Letras Pablo García Baena, en una de sus últimas entrevistas en profundidad, firmada por Rosa Luque (Diario Córdoba, 8 de julio de 2012), una periodista que, conociéndolo bien, supo transmitir aún mejor su pensamiento y su actitud ante la vida. Tras décadas de polémicas continuadas sobre el futuro de Córdoba, este poeta universal con alma de ermitaño dirimió el debate con pragmatismo y buen tino, necesitado sólo de dos frases. Pero, ¿cómo hacerlo a entender a quienes confunden la ciudad con un escenario permanente, su austeridad de raza con el afán estrafalario de emulación, su nobleza de siglos con la vulgaridad más explícita? Es difícil, sin duda; no tanto por la semántica estricta de las palabras, sino por la impermeabilidad ante lo que representan e implican por parte de quienes la han convertido en un híbrido absurdo, incapaz de reconocerse. Córdoba necesita reencontrar su rumbo y reivindicarse a sí misma.

Según las cifras del Ministerio de Cultura, el Patrimonio Histórico español generaba cada año, antes de marzo de 2020, decenas de miles de millones de euros de beneficio, frente a una inversión comparativamente mínima, que podría ser incluso inferior si las distintas Administraciones se coordinaran como de hecho manda la ley ${ }^{12}$. Y, por supuesto, Córdoba no era excepción, por más que su imagen urbana aparezca actualmente desenfocada a causa del folklorismo anacrónico. La in-

\footnotetext{
${ }^{11}$ Estas mismas cuestiones han sido también observadas, recientemente y sin ambages, a nivel global, por P. Morín y R. Barroso, que llegan a hablar de "orgía de destrucción", ante la pasividad, la complacencia, o el mirar hacia otro lado de éstos y de aquéllos (Morín y Barroso, 2014,320 ss.).

${ }^{12}$ Artículo 4 de la Ley de Patrimonio Histórico Andaluz, en su reformulación de 2007.
} 
vasión sin precedentes de bares, terrazas y veladores en sustitución del la vida y el comercio tradicionales terminarán por convertir la ciudad en una pura cantina; el caos circulatorio; las actitudes incívicas; su aparente falta de rumbo..., son sólo algunos aspectos de un problema de enorme alcance que afecta también a otras urbes (Barcelona o Málaga por ejemplo ya reaccionaron) y degrada a marchas forzadas la calidad de vida de quienes habitan el centro histórico, sometidos a una permanente carrera de obstáculos.

Lo han señalado algunas de las asociaciones ciudadanas locales: si se expulsa a los vecinos en beneficio de la industria hotelera y restauradora, se acabará convirtiendo el corazón de la urbe en un parque temático con el negocio como único hilo conductor, provocará un desastre de extraordinarias e irreversibles consecuencias en el patrimonio, la cultura y las formas cordobesas de ser y de vida, que son los que atraen cada año a decenas de miles de turistas. Hacen falta, pues, reflexión urgente, medidas de verdad correctoras, empatía para entender que una ciudad la hacen quienes la habitan y la dotan de contenido y de alma. Si se siguen primando criterios crematísticos, Córdoba acabará traicionándose a sí misma y pasará a ser otra cosa; legítima quizás, pero desde luego muy alejada de la que habría sido su evolución natural.

Junto con la fiesta de los patios no existe mejor espacio para detectar, en toda su dimensión, el volumen ingente de personas que pasan a diario por Córdoba (decir "visitan" sería demasiado generoso, si tenemos en cuenta la fugacidad de sus estancias) que el entorno inmediato de la Mezquita, donde a veces cuesta, literalmente, transitar las calles ${ }^{13}$. Esa multitud, cuya presencia debería ser suficiente para garantizar a Córdoba uno de los primeros puestos en el ranking de las ciudades más ricas de España ${ }^{14}$, se ve incrementada los fines de semana por los propios cordobeses, que se echan en masa a la calle animados por eventos del más variado tenor, despedidas de solteros/as, bodas, novatadas, viacrucis, triduos, procesiones, novenas, o el simple placer de estar con otra gente. Algo que llega con frecuencia a saturar el espacio.

Se suman a esta cuestión agresiones mucho más explícitas y contundentes al casco histórico en sentido estricto, como la celebración de carreras de coches ${ }^{15}$ (Fig. 5), o la disposición en él de los palcos de la carrera oficial de la Semana Santa. Esto es instrumentalizar el patrimonio, un atentado contra el mismo. Los problemas de seguridad, contaminación visual y sonora, capacidad de carga, accesibilidad, evacuación o excesos se agravan por tratarse de un espacio extremadamente frágil, del que peligran su ética y su estética. No sirve el argumento de que otras ciudades también lo hacen. Cada urbe es única, y la excepcionalidad de Córdoba se percibe a cada paso. Trasladar la carrera oficial a esa zona no es sino incrementar la focalización de la imagen urbana en cuatro calles que, en el fondo, representan sólo una mínima parte de la ciudad. Sería más lógico y estratégico apostar por la descentralización, por deslocalizar el eje de atención del turismo y multiplicar su dispersión por el casco histórico, evitando los excesos; algo a lo que ayudan de manera importante los patios durante su fiesta de mayo.

Potenciar determinadas postales urbanas puede ser legítimo y hasta loable, pero nunca a costa del acervo patrimonial colectivo, que como bien recogen las grandes cartas internacionales -en particular la Convención de Faro, de 2005- y las leyes nacional y autonómica tenemos la obligación de investigar, conservar y transmitir, acrecentado. La crisis del Covid se está encargando de demostrar que el turismo como única alternativa económica puede ser pan para hoy y hambre generalizada para mañana. De ahí la necesidad de revisar el modelo en aras de otro más transversal, estructural y sostenible.

Córdoba es nudo privilegiado de comunicaciones, dispone de un acervo patrimonial incomparable, y es emprendedora, creativa, puntera, acogedora, sorprendente, exclusiva. Sin embargo, a la hora de generar su marca pesan más los aspectos negativos: abúlica, discreta, descoordinada, políticamente ingobernable, errática, incívica, incierta. Su casco histórico preserva aún ese cierto sabor a pueblo tan característico; permite ir andando a todas partes si no se tiene pereza; sus piedras desgastadas evocan la memoria de tantos otros que las pisaron antes, y de noche es fácil dejarse seducir por los efluvios de jazmines, madreselvas o damas y galanes de noche. No cuenta, sin embargo, con buen comercio; muchas de sus calles no permiten la entrada de ambulancias o coches de bomberos; aparcar es odisea sólo combatible con la compra o alquiler de una plaza de garaje en la que es fácil quedar bloqueado; mientras la reiteración de espectáculos y verbenas deterioran la calidad de vida de los vecinos. Es, pues, ciudad bifronte, en la que suelen convivir a diario las dos caras de una misma moneda.

Hasta que estalló la pandemia, creía haber descubierto en el turismo la gallina de los huevos de oro;

\footnotetext{
${ }^{13}$ Entrego este texto en plena progresión de la segunda oleada pandémica de 2020, y en estos momentos el entorno citado destaca por lo contrario: parece un simple decorado del que han huido los extras una vez terminado el rodaje.

${ }^{14}$ ¿Por qué entonces no es así...?; he aquí una pregunta de hondo calado, que nadie parece tener demasiado interés en responder.

${ }^{15}$ La celebración en la primavera de 2017 del rally Sierra Morena en pleno corazón del casco histórico de Córdoba, declarado por partida doble Patrimonio de la Humanidad por la UNESCO, excedió cualquier lógica. Es muy llamativo que, en un ejercicio de responsabilidad encomiable sin demasiados precedentes en Córdoba, estén siendo las asociaciones ciudadanas, los representantes sociales, los cordobeses mismos, quienes denuncien tales tropelías.
} 


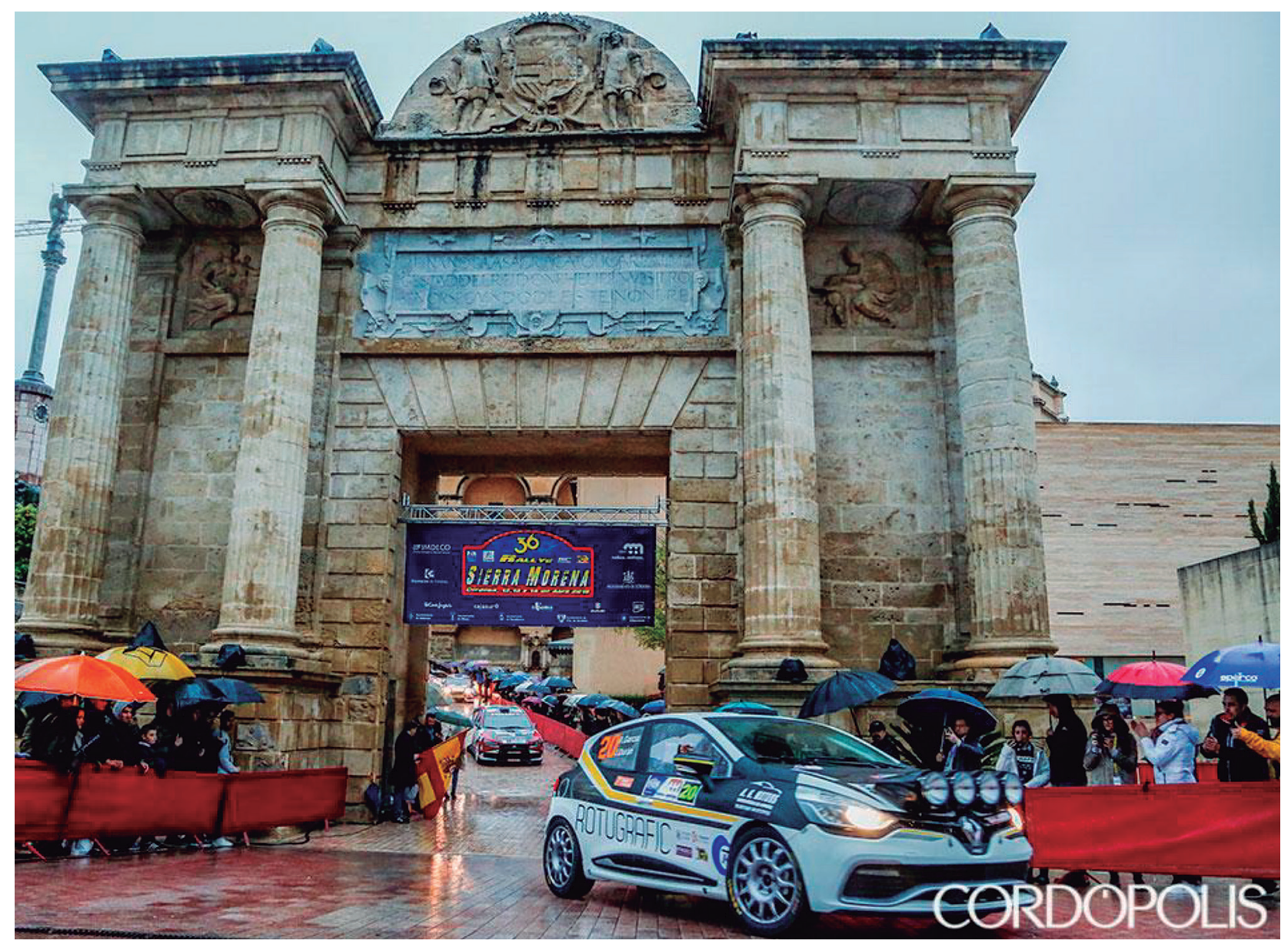

Fig.5. Córdoba. Prueba deportiva celebrada en pleno corazón de su entorno monumental declarado por partida doble Patrimonio de la Humanidad (Fotog. Cordópolis). / Córdoba. Sporting event held in the heart of its monumental district which was twice declared a World Heritage List (Photog. Cordópolis).

la hostelería se había convertido en su cruz de guía; asistía, impávida, a la desnaturalización y el colapso de su centro histórico; seguía sin disponer de un proyecto conjunto de futuro, incapaz de diseñar actuaciones al margen de los ciclos políticos; permanecía indiferente a la transformación de sus espacios urbanos en beneficio del ruido, las tabernas y un epicureísmo feroz y mal entendido; aplaudía que masas informes invadieran sus calles a riesgo de echar de ellas a quienes las habitan; derrochaba patrimonio en absoluta, irresponsable y temeraria impunidad, confiada en el potencial de la Mezquita y los patios... Sin embargo, la Marca Córdoba no puede ser la duda metódica, ni la eterna displicencia, o la polémica por la polémica, sino la abstracción, la transversalidad, la reivindicación rotunda de su idiosincrasia, la motivación, el consenso. No existen las fórmulas mágicas; sólo el trabajo y el tesón en pro de una idea compartida; porque en último término el patrimonio lo generan, alimentan y singularizan los pueblos, que le dan valor. ¿Existe mejor marca que la coherencia...?

Córdoba es resultado paradigmático de un proceso de síntesis cultural, urbanística y arquitectónica que, a través precisamente del uso de materiales constructivos tomados de su propio entorno (básicamente, piedra, tierra, madera y cal), del diseño de calles y plazas de forma que el sol no las maltrate, de concebir la vida hacia adentro en torno al patio, de aprovechar las infinitas posibilidades que ofrece su extraordinaria abundancia en agua, ha sabido generar una forma de vida adaptada a los rigores del clima, a su extremismo meteorológico secular, a su necesidad de bajar unos grados el calor imperante la mitad del año, a su carácter abierto y socializador, tan dado a la vida en el barrio. Un prototipo de ciudad histórica a la que es posible acercarse de mil formas diversas, y que si rompe su equilibrio terminará por deshumanizarse.

Las avalanchas de turistas -que un día volverán, aun cuando a día de hoy sea difícil hacer previsiones de nada- son también resultado de la promoción nacional e internacional que se está haciendo de la ciudad, de sus cuatro reconocimientos como Patrimonio de la Humanidad, del trabajo de muchísima gente. Quienes la visitan suponen un aporte extraordinario de dinero que repercute en un amplio espectro de parcelas económicas, vitales en su apuesta sin reservas por el sector 
servicios, en su renuncia a cualquier pretensión industrial. Sería temerario defender lo contrario. La pregunta es si todo ello se traduce en empleo de calidad, si los beneficios económicos generados revierten de verdad en la mejora del producto, si existe voluntad de renovar de forma sostenida su oferta, si se emplean suficientes esfuerzo y dinero para potenciar el verdadero leitmotiv de la urbe, justificación de sus ecos universales y clave de su retroalimentación permanente: el patrimonio. Y la respuesta ha de ser categórica: no.

Ni la ciudad podrá soportar por mucho más tiempo el crecimiento exponencial e imparable de un turismo aluvional que acaba llevándose una imagen equívoca de la misma, ni le conviene creer que está todo hecho. De ahí la importancia de reconducir el modelo. Lo ideal sería un turista que pudiera recorrer Córdoba sin aglomeraciones y en silencio, amparado por las primeras luces del alba, los colores en explosión del centro del día o la calma tabernaria de la tarde; disfrutando en un patio de un rato de charla sosegada con quienes viven en él y lo cuidan. Hablo de patios reales, no de atrezzo. Esa persona volvería, y cuando lo hiciera querría repetir su comunión, seguir indagando en las claves existenciales de una urbe que es puro duende. Cuesta creer que esta sensación la comparta quien ha recorrido las calles estrechas del casco histórico durante tres horas, adocenado cual oveja tras la sombrilla del o la guía de turno. El objetivo ha de ser el turismo cultural de calidad, ansioso por saber, deseoso de vivir nuevas experiencias, impaciente por sumergirse de lleno en la historia y la etnografía de la sociedad que lo acoge; no estacional, por tanto. Dicho de otra manera: caben otros modelos, más allá de ser invadidos.

Toda sociedad que se precie debe reivindicar su derecho fundamental e inalienable a la salud, el descanso y la integridad física y mental; un espacio urbano tranquilo, silencioso, ordenado, limpio, pulcro y educado, en el que convivir no implique molestias para nadie, sino solaz y gratificación; máxime, cuando hablamos de una ciudad como Córdoba, que respira poesía por sus cuatro costados. El silencio también es cultura; matiz definitorio; invitación a la lectura y la reflexión sosegada, a la charla compartida; símbolo de introspección, puerta de la sabiduría, espejo de poetas. Paradójicamente, las autoridades no paran de abrir la mano en lo que se refiere a las concesiones al sector hostelero. Lo demuestra la nueva regulación de actividades recreativas aprobada por la Junta de Andalucía en el verano de $2018^{16}$.

Nuestros cascos históricos están ya tan invadidos por las terrazas y los locales de ocio, incrementados por los intentos un tanto fútiles de evitar el colapso económico -como si no existieran más fuentes de reactivación económica- durante la crisis del coronavirus ${ }^{17}$, que cuesta entender su proliferación salvaje; sobre todo cuando ya en 2016 los Defensores del Pueblo españoles en su conjunto denunciaron las agresiones acústicas como un problema gravísimo de salud colectiva $^{18}$, en línea con la Directiva Europea del Ruido ${ }^{19}$, la Constitución y el Estatuto de Andalucía. El respeto y la cultura no merecen su nombre si se construyen a costa del abuso sobre una parte representativa de la sociedad, aun cuando ésta no tenga más fuerza que la de su humilde voto. Los derechos propios empiezan siempre donde terminan los ajenos.

A todo ello, por último, se suman las complicaciones derivadas del tráfico rodado. Este es quizás el aspecto más doloroso, lacerante e incomprensiblemente surrealista que soportan quienes viven en el casco viejo de la ciudad. Los procesos de peatonalización, con ser un regalo para los ciudadanos, resultan siempre traumáticos para quienes se les priva de poder llegar en coche hasta su casa. Basta un poco de sentido común para entender que uno de los principios fundamentales de la urbanística moderna consiste en aligerar el tráfico del corazón de las ciudades desplazándolo hacia las rondas y los grandes ejes viarios. Por eso resulta tan inexplicable que, tras la última remodelación del mismo acometida por el Ayuntamiento local, para salir o entrar de muchas de las cocheras de barrios tan poblados y emblemáticos como la Axerquía haya, necesariamente, que pasar por el centro neurálgico de la urbe: la plaza de Las Tendillas; con lo que esto supone de densificación de la circulación en calles y plazas poco aptas para ello, de molestias para los peatones, y de enfado lógico y más que justificado para los usuarios, que ven cómo de manera sistemática se les dificulta su día a día, se les expulsa de su entorno en beneficio de un nuevo modelo urbano que prima los usos turísticos y la desnaturalización frente a los intereses de quienes lo habitan y lo construyen desde hace siglos como entidad urbana. Sin olvidar que tales cortapisas afectan también a los propios turistas, condenados a dar tumbos con sus coches durante horas antes de que consigan acceder a sus hoteles respectivos; a los despistados que caen en las garras inmisericordes de las cámaras de vigilancia y punición; a los centros de enseñanza y el transporte escolar, y a cualquier tipo de urgencia, médica o sobrevenida.

Añádanse a los problemas ya indicados la suciedad y el desorden; la falta de señalización adecuada o

\footnotetext{
${ }^{16}$ https://www.juntadeandalucia.es/boja/2018/150/13. Fecha de consulta: 29 de noviembre de 2018).

${ }^{17} \mathrm{Mi}$ argumentación debe entenderse al margen de esta última. En su transcurso, la hostelería ha sido sin duda uno de los sectores profesionales más castigados, razón por la que en momentos de mayor relajación se abrió bastante la mano. Sin embargo, la crisis no debe ser excusa para volver por los mismos fueros cuando todo pase.

$18 \mathrm{https}$ //www.defensordelpueblo.es/noticias/decalogo-de-los-defensores-del-pueblo-contra-el-ruido/ (fecha de consulta 29.11.2018).

19 https://eur-lex.europa.eu/legal-content/ES/ALL/?uri=CELEX\%3A32002L0049 (fecha de consulta 29.11.2018).
} 
de servicios en el centro histórico; la multiplicación de solares abandonados que además de afear se convierten con el paso del tiempo en nidos de ratas o de toxicómanos; el cableado omnipresente y desafortunado en fachadas, calles y plazas; la proliferación de antenas y aparatos de aire acondicionado; la cartelería invasiva en pleno corazón de la zona Patrimonio de la Humanidad; la mendicidad de mayores y niños; la economía sumergida, que por regla general genera empleo de muy baja calidad, precarios y mal pagados; el turismo de borrachera, indómito y desmesurado; la cultura del jolgorio, la gentrificación salvaje..., y se obtendrá una imagen mucho más completa de los problemas que padece actualmente la ciudad. De ahí la necesidad de un proyecto holístico que la gestione y la potencie en su integridad.

De entre todas las limitaciones señaladas destaca, de hecho, una de trascendencia inusitada que, aun cuando ya apuntada, merece la pena individualizar: el abandono del casco histórico por parte de sus habitantes tradicionales en beneficio de la hostelería, las multinacionales y los compradores de mayor poder adquisitivo o los apartamentos turísticos; en un ejemplo paradigmático y agudo de gentrificación. Sirva como ejemplo conspicuo al respecto el entorno de la Mezquita-Catedral, declarado Patrimonio de la Humanidad por partida triple (si incluimos los patios), casi vacío ya de residentes, que han vendido o venden sus casas al mejor postor para que puedan ser explotadas turísticamente, cansados de tantas trabas y tanta molestia diaria. Esto viene provocando a su vez, de forma silenciosa pero imparable, la desaparición de tipologías arquitectónicas milenarias basadas en el esquema de la casa-patio en beneficio de locales comerciales que, a su vez, falsean o enmascaran la imagen urbana, disfrazándola.

Esta cuestión fue ya denunciada en 2008 por G. Palmieri (2008), en un ensayo sobre Córdoba como ciudad histórica que mantiene plena vigencia. En un proceso alarmante de consecuencias insospechadas el fenómeno se va haciendo extensivo al resto del casco histórico, reconvertido para negocios diversos al servicio de una burbuja turística que ha estallado con la crisis del coronavirus provocando un desastre descomunal ante la falta de alternativa; transformado aquél poco a poco en puro cascarón de huevo que tal vez mantendrá durante algún tiempo la vida, pero a costa de su desnaturalización, de alterar por completo su tradición y romper su equilibrio, de expulsar piano piano y criminalmente a los vecinos, que son quienes le han dado su carácter singular, construyéndolo y viviéndolo en primera persona durante siglos.

Existen mecanismos normativos como el Plan Especial para la Protección del Casco Histórico que deberían estar velando por que esto no ocurriera, pero dicho documento es de 2003, y las cosas han cambiado mucho en la ciudad desde entonces, especialmente en los últimos cuatro o cinco años, cuando el turismo pasó de ser potencial fuente de riqueza a implacable invasión. Los responsables políticos no tendrán, pues, más remedio que tomar antes o después cartas en el asunto, por más que ello termine enfrentándoles al sector de la hostelería, cuyo papel en la salvaguarda y enriquecimiento del discurso patrimonial y en el empleo de calidad no acaba de estar claro. En caso contrario será la ciudadanía la que se pronuncie. Córdoba no está preparada para una transformación tan radical. De ahí las denuncias, como la de Marta Jiménez cuando hablaba hace algún tiempo de la "dysneificación de la Judería y el Alcázar Viejo, el monocultivo comercial, la pérdida de identidad, la gentrificación, la transformación del paisaje urbano o las heridas de muerte a la vida social de los barrios"20.

Es hora de escuchar lo que esas mil voces gritan, de sentarse a reflexionar sobre las claves del mensaje que transmiten, y reaccionar en consecuencia antes de que todo sea irreversible. La responsabilidad institucional al respecto, por más que obedezca a claves políticas o ideológicas -quizás también a determinados intereses-, es enorme; incluso aunque se trate de pura ignorancia, en la que algunos persistirían en enrocarse. Una sociedad que no respeta la herencia patrimonial -material e inmaterial-, que ha recibido, cuidándola y engrandeciéndola sin pervertirla, es una sociedad abocada a perder su anclaje en la historia, que no se respeta. Córdoba debería, pues, renunciar a su discreción y abulia seculares, y reivindicar activamente su esencia como cultura. Lo que está ocurriendo es muy grave.

En este sentido se veía venir; y hasta cierto punto es lógico que haya sido en Venecia, porque la ciudad, con sólo cincuenta mil habitantes, lleva soportando una sobrecarga turística desorbitada desde hace demasiado tiempo. Treinta millones de visitantes al año, en un conjunto urbano inestable por definición que corre el peligro de verse engullido por las aguas y se cae de puro bello, son una barbaridad incluso si se miran desde un punto de vista meramente crematístico. Hablo de los tornos que el Comune de la Serenísima colocó hace algún tiempo con carácter provisional en varios puntos neurálgicos de acceso al corazón de su casco histórico, a fin de limitar, o por lo menos intentarlo, un flujo de personas que parece regenerarse a cada segundo (Fig. 6). Como era de esperar, las reacciones fuero variadas, y en muchos casos furibundas. Los hosteleros y comerciantes vieron peligrar la gallina de los huevos de oro, y una parte de la población se manifestó en contra de convertir su lugar en el mundo en una suerte de parque temático. Pero, ¿cómo actuar ante unas avalanchas de gente que no paran de crecer?

\footnotetext{
${ }^{20}$ M. Jiménez, "Mordor", en Diario Córdoba de 18/05/2017 (https://www.diariocordoba.com/noticias/opinion/mordor_1147238.html)
} 


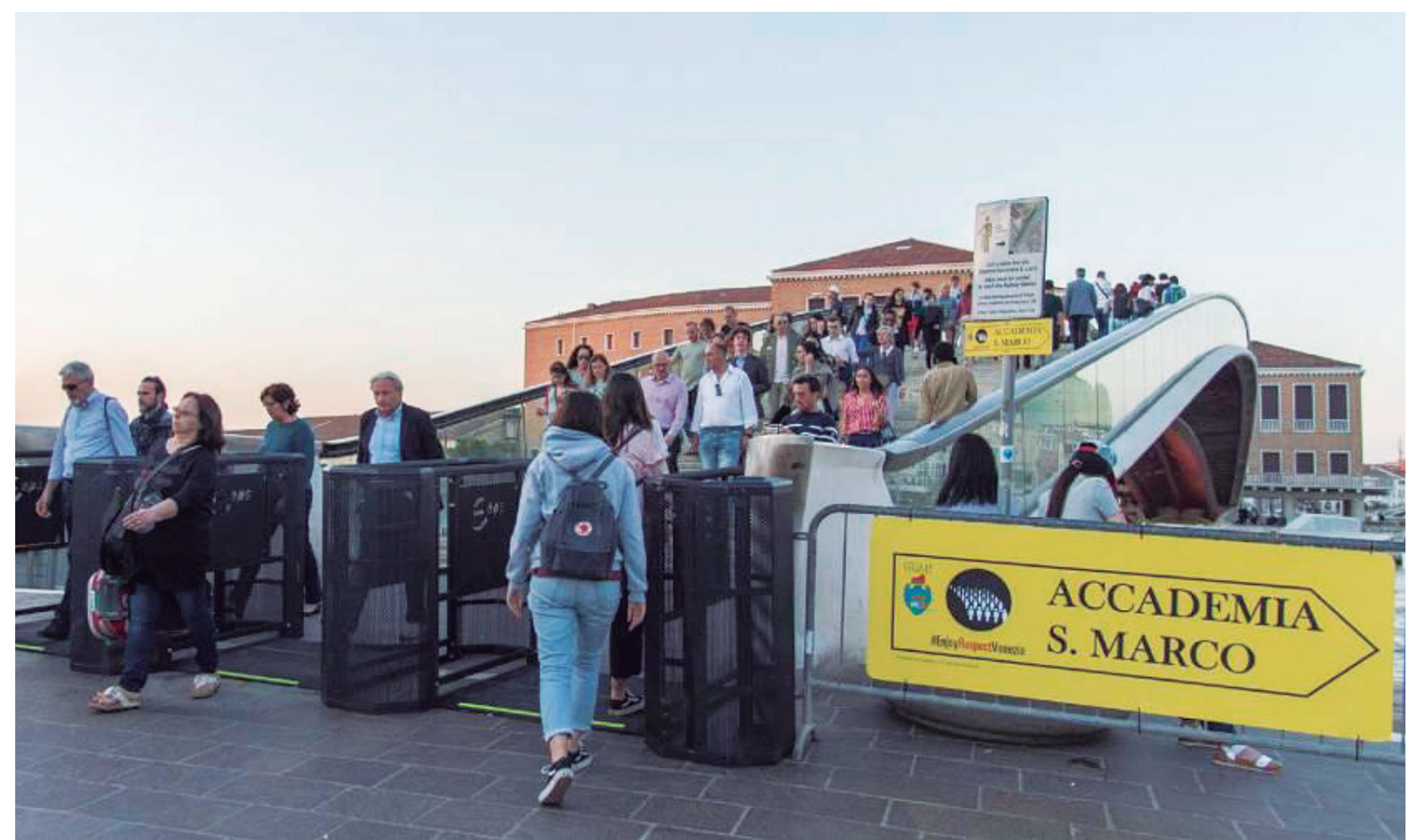

Fig.6. Tornos en Venecia, motivo de polémicas y protestas por lo que representan de tematización de la Perla del Adriático (Fotog. Efe; El País, 29-04-2018). / Turnstiles in Venice are a source of controversy and protests because they transform the "Pearl of the Adriatic" into a sort of theme park (Photo Efe; El País, 0429-2018).

Nuestros centros monumentales no están preparados para soportar tantos miles de turistas, que en el deseo legítimo de disfrutarlos acaban sin embargo conculcando su naturaleza, poniendo en riesgo un paisaje patrimonial frágil y no renovable, muy afectado ya por las intervenciones en él para ser expuesto, y extremadamente vulnerable a la acción de los viajeros por lo que ello implica de sobreexplotación y de mixtificación. Sirva recordar al efecto eventos multitudinarios en Córdoba, como la fiesta de las Cruces, mercantilizada hasta extremos alarmantes, o la de los patios: desde su reconocimiento como Patrimonio Inmaterial de la Humanidad por la Unesco ha desvirtuado su naturaleza y terminado por derivar en algo distinto tras ser invadida por una muchedumbre ansiosa que ha expulsado de ella a muchos cordobeses (Fig. 7). La masificación tiene efectos publicitarios y económicos inmediatos, pero acaba por provocar el rechazo y la huida de la población residente, la pérdida de valor. De ahí sus riesgos.

Obviamente, la burbuja turística no es problema exclusivo de Córdoba. La relativa estabilidad de los países del Occidente de Europa, y más en particular de España, antes de la crisis del Covid, los ha convertido en foco de atracción para un turismo nacional e internacional que huye del miedo y la inseguridad buscando el sol y el tipismo, y que cuando se convierte en multitudinario acaba por transformar su experiencia en relación con el bien visitado en "idolatría estática e irracional", que dejó dicho M. Himmelmann (1981, 78). Se entiende por tanto la necesidad de poner límites; de controlar el proceso aprovechando la bonanza para crear estructura; de apostar por la oferta cultural de calidad en lugar de dar entrada a hordas de gente que se van tras un contacto superficial; de potenciar lo propio en aras de la singularidad, evitando que Córdoba desdibuje más sus perfiles; de no dejarse cegar por el dinero fácil y hacer ciudad pensando en el futuro...; porque el futuro llegará, y puede cogerla con el paso cambiado.

No cabe apostar, en definitiva, por la industria turística como única alternativa. Conviene diversificar, enriquecer el tejido económico, apoyar sin reservas líneas de trabajo complementarias que enraícen con fuerza en lo genuino y singular, porque hablamos de un patrimonio común que los cordobeses han hecho suyo dotándolo de un valor añadido, garante de su supervivencia. Una urbe ideal es la que evoluciona y crece fiel a sí misma y su esencia de siglos, la que hace más fácil y agradable la existencia de sus habitantes, la que facilita su devenir cotidiano, la que les regala con espacios públicos confortables y acogedores, la que piensa en todos y cada uno de ellos sin primar eventuales intereses económicos, partidistas, coyunturales o ideológicos sobre el bien común, la casuística colectiva o la esencia cultural y las tradiciones de quienes -ellos sí- hacen ciudad a base de vivirla. 


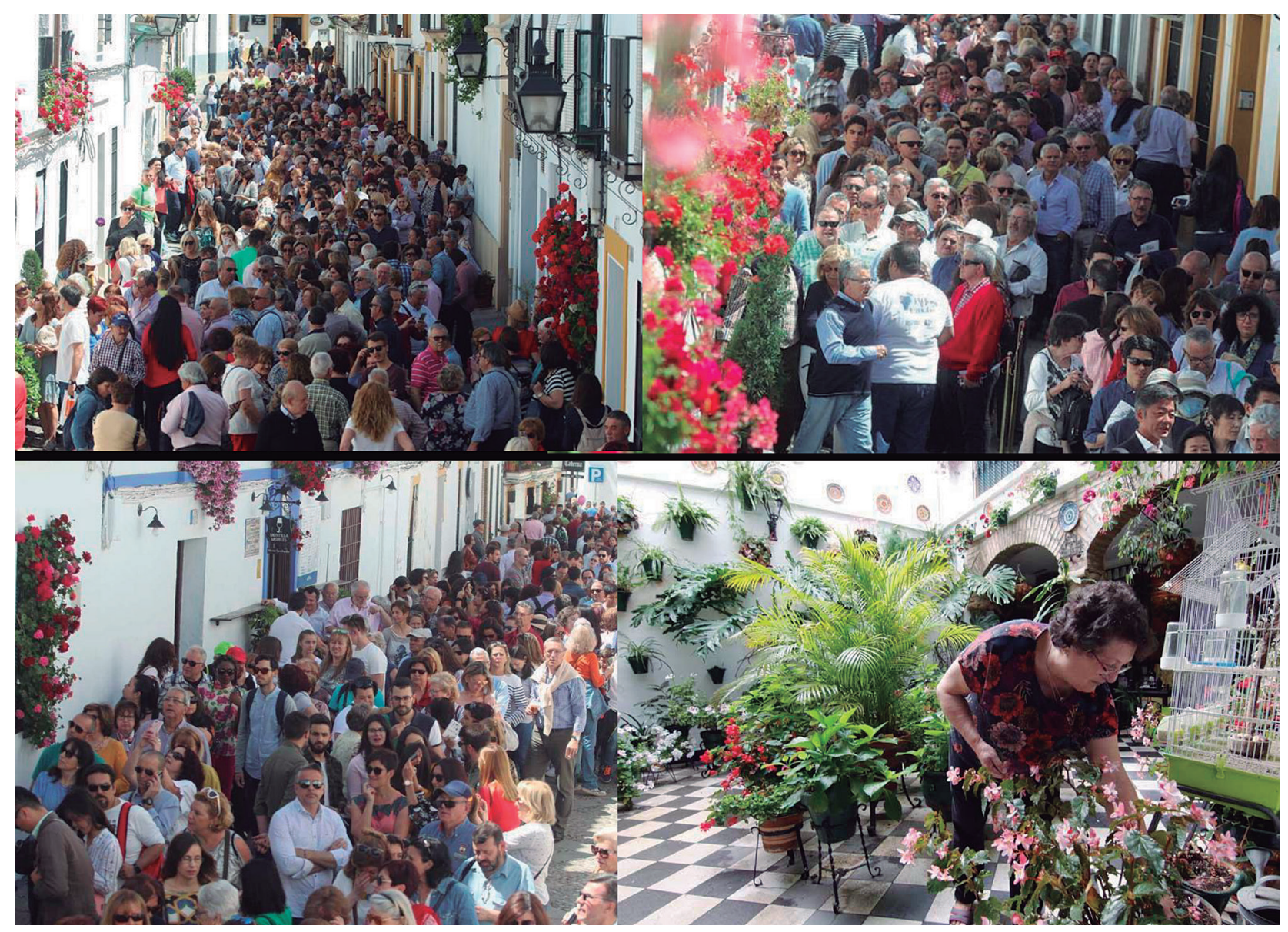

Fig.7. Escenas de masificación durante la fiesta de los patios en Córdoba, que contrastan grandemente con el espíritu de disfrute familiar e íntimo de estos últimos (Fotog. Sánchez Moreno, Diario Córdoba). / Scenes of overcrowding during Córdoba's Patio Festival. This is at odds with the traditional intimate family spirit of the city (Photo Sánchez Moreno, Diario Córdoba).

\section{EL ETERNO DESAFÍO DE POTENCIAR LO PROPIO (A MODO DE RECAPITULACIÓN)}

Más allá de la masificación en sí misma, provocada por el turismo de aluvión al que la crisis sanitaria provocada por el coronavirus puso fin de manera tan inesperada como traumática, los peligros de lo que está ocurriendo al respecto en muchas de nuestras ciudades históricas son importantes y variados; entre ellos:

- la perversión de los fines últimos del turismo, entendido en sentido estricto desde una posición de ortodoxia histórica y también semántica;

- la 'tematización' de los espacios naturales, de los conjuntos históricos y de los sitios arqueológicos, obviando así su carácter integral y las exigencias naturales de diacronía y transversalidad;

- la creación de discursos bastardos, con el peligro más que evidente de caer temerariamente en los tópicos y el costumbrismo anacrónico, exacerbándolos;

- la pérdida del valor histórico acumulado, hasta convertir lo auténtico y genuino en puro artificio de cartón piedra, o incurrir en la mimetización global;
- la insostenibilidad, derivada del turismo masivo, el encarecimiento de los centros históricos, la expulsión de los residentes, el despoblamiento en beneficio de la hostelería y la pura saturación, a punto siempre de rebasar peligrosamente la capacidad de carga;

- la primacía de la forma sobre el fondo, de lo bello sobre el valor patrimonial, del artificio y la complacencia sobre la tradición, la autenticidad, la preservación, la investigación y el equilibrio, menos rentables.

En definitiva, no cuestiono la fiesta de los patios, de belleza, raigambre y proyección indiscutibles. Abrir las puertas de una casa para que durante dos semanas desfilen por el corazón de la misma decenas de miles de desconocidos sin otra contrapartida, en principio, que la de socializar el tesoro familiar más valioso, es de una generosidad y un altruismo poco frecuentes. No obstante, una de las claves determinantes de los patios domésticos desde el principio de los tiempos, o al menos desde que tenemos constancia de ellos, ha sido la de su concepción como espacios destinados a la intimidad de la familia, a la oxigenación de la casa, al disfrute del ocio y de lo personal, en una clara evo- 
cación del paraíso en la tierra. Nada, pues, que ver con su invasión por multitudes, ni siquiera temporalmente, por más que la esencia de muchos de ellos haya sido la vida en comunidad. Son, pues, los antropólogos, los urbanistas, los geógrafos, los historiadores, y por qué no, también los arqueólogos, los llamados a establecer con urgencia, desde una perspectiva interdisciplinar, rigurosa, fundamentada y de consenso, en qué medida una fiesta así conculca o no la naturaleza más profunda y definitoria de tales bienes.

Después de su declaración como Patrimonio Inmaterial de la Humanidad por la UNESCO, la apertura al público de los patios cordobeses se ha convertido en uno de los activos más importantes de Córdoba, y, junto a la Mezquita y Medina Azahara, en su tirón más importante para el turismo, por lo que sería suicida renunciar a ella. Ahora bien, la ciudad ${ }^{21}$ debe reflexionar de forma perentoria sobre cómo abordar dicha fiesta de cara al futuro y limitar su alcance; no ya sólo en cuanto a la afluencia de público, sino también en cuanto al inventario, la conservación y los usos de dichos espacios. Además, por supuesto -dada la proliferación de discursos espurios-, de velar por su autenticidad, por que no pierdan la esencia y acaben mostrándose al mundo como una simple tarjeta postal, hermosa sin duda pero carente de vida y de contenido; porque un patio es oasis de silencio y aromas, rumor gozoso de agua y savia, doblones de luz entre jazmines, ecos atávicos de ronda, claros insinuantes de luna, susurros reposados de novena, calma esponjosa de siesta, sigilos secretos de madrugada...; nunca bullicio, exceso de decibelios, derivaciones adulterinas, gritos o ruido, por más que sean espacios privilegiados de convivencia. Para eso ya está el resto de la ciudad.

Que las sociedades evolucionen resulta sano, natural y hasta deseable; pero ¿es realmente necesario que lo hagan a costa de conculcar su pureza, renunciando a sí mismas...?

\section{BIBLIOGRAFÍA}

Blanco Guzmán, R., 2018. Vivir en la Córdoba islámica: de la fitna a la entrada en la ciudad de Fernando III. En: Vaquerizo Gil, D. (Coord.), La historia de Córdoba a través de sus barrios (I). De los vici romanos a los arrabales islámicos, Córdoba, 351-397.

Casal García, M. T., 2020. El arrabal de Šaqunda: un modelo temprano de urbanismo omeya en el Mediterráneo occidental. Tesis doctoral inédita, Universidad de Córdoba/lH-CCHS (CSIC).

Castro Carrera, J.C., 2011. Sociedad, cultura... arqueología. En: Almansa, J. (Ed.), El futuro de la Arqueología en España, San Fernando de Henares (Madrid), 49-53.
Clapés, R.; Rubio, M.; Castillo, F., 2019. Nuevos datos sobre la producción oleícola en Colonia Patricia: el asentamiento romano de La Arruzafa (Córdoba), Anales de Arqueología Cordobesa 30, Córdoba, 187-208.

De la Bandera, M.L., Ferrer, E. (Coords.), 2016. El Carambolo: 50 años de un tesoro. Sevilla.

Escobar, J.M., 1989. Córdoba en la Baja Edad Media. Evolución urbana de la ciudad, Córdoba.

Fernández Gallardo, I. (2015), La declaración de Patrimonio Mundial y su influencia en la difusión del Patrimonio Arqueológico. El caso de Córdoba. Trabajo Fin de Máster (dirigido por A., Castillo Mena), Universidad Complutense de Madrid.

Flora, N., 2015. Pompei. Modelli interpretativi dell'abitare. Dalla domus urbana alla villa extraurbana. Siracusa.

Fuertes, M.C., Hidalgo, R., 2005. El yacimiento de Cercadilla en Córdoba. Un proyecto de conservación complejo.En: III Congreso sobre musealización de yacimientos arqueológicos. De la excavación al público. Procesos de decisión y creación de nuevos recursos, 31-37. Zaragoza.

García Gómez, E., 1976. Elogio del Islam español (Risala fi fadl Al-Andalus), por Al-Saqundi. En: Andalucía contra Berbería. Reedición de traducciones de Ben Hayyan, Saqundi y Ben Al-Jatib, 43-141. Barcelona.

González Gutiérrez, C., 2018. Vivir en la Córdoba islámica: la etapa emiral. En: Vaquerizo Gil, D. (Coord.), La historia de Córdoba a través de sus barrios (I). De los vici romanos a los arrabales islámicos, 299-322. Córdoba.

Grande León, A., 2016. El patrimonio arqueológico. Investigación, conservación, gestión y difusión del patrimonio en la era digital. En: Vaquerizo, D., Ruiz, A., Delgado, M. (Eds.), Rescate: Del registro estratigráfico a la sociedad del conocimiento: El patrimonio arqueológico como agente de desarrollo sostenible, Vol. I, 307-321. Córdoba.

Gros, P., Torelli, M., 2007. Storia dell'urbanistica. II mondo romano. Roma.

Gutiérrez Lloret, S., 2012. Gramática de la casa. Perspectivas de análisis arqueológico de los espacios domésticos medievales en la península Ibérica (siglos VII-XIII). Arqueología de la Arquitectura 9, 139-164

Hidalgo, R. (Ed.), 2016. Las villas romanas de la Bética. 2 vols. Sevilla.

Himmelmann, N., 1981. Utopia del pasato. Archeologia e cultura moderna. Bari.

Jashemski, Wilhelmina F., Gleason, Kathryn L., Hartswick, Kim J., Malek, Amina-Aïcha (Eds.), 2017. Gardens of the Roman Empire. Cambridge.

León Muñoz, A., Vaquerizo, D., 2012. Un nuevo modelo de gestión de la Arqueología Urbana en Córdoba. En: Beltrán, J., Rodríguez, O. (Eds.), Hispaniae Urbes. Investigaciones arqueológicas en ciudades históricas, 321-361.Sevilla.

Márquez, F.S., 2013. La Córdoba de Antonio Cruz Conde, el Alcalde que cambió la ciudad. Córdoba.

\footnotetext{
${ }^{21}$ Y por tal entiendo las Administraciones responsables, que indefectiblemente deben huir de las decisiones políticas para ponerse en mano de los especialistas y de los agentes implicados. Sólo entonces, tras escuchar a todos y estudiar a fondo el problema, será posible llegar a soluciones fundamentadas con vocación de sostenibilidad.
} 
Monzo, P., 2008. El problema del aislamiento de los bienes inmuebles arqueológicos. La búsqueda del significado. Romula 7, 331-353.

Monzo, P., 2010. Patrimonio arqueológico en la ciudad de Sevilla: cuidados y olvidados. En: Hidalgo, R. (Coord.), La ciudad dentro de la ciudad. La gestión y conservación del patrimonio arqueológico en ámbito urbano, 107-142.

Morín, J., Barroso, R. 2014. De la arqueología de la mortadela a la arqueología de la resistencia. La democratización fallida de la Arqueología española. Arqueoweb 15, 315-321. http:// pendientedemigracion.ucm.es/info/arqueoweb/pdf/15/MorinBarroso.pdf

Moya, P., 2010. Grandezas y miserias de la arqueología de empresa en la España del siglo XXI. Complutum 21(1), 9-26.

Muñoz Molina, A. 2009. Córdoba de los Omeyas ( $2^{\mathrm{a}}$ ed.). Sevilla.

Neira Jiménez, L., 2018ª . El mosaico pavimental en Corduba CoIonia Patricia: sociedad, mito e ideología. En: Vaquerizo Gil, D. (Coord.), La historia de Córdoba a través de sus barrios (I). De los vici romanos a los arrabales islámicos, 145-186. Córdoba.

Neira Jiménez, L., 2018b. Océano en los mosaicos romanos. A propósito de un pavimento de Colonia Patricia. Anales de Arqueología Cordobesa 29, 157-176.

Palmieri, G. M., 2008. Imagen de una ciudad del tercer milenio. Límites, obstáculos, necesidades y oportunidades para la ciudad de Córdoba. Arte, Arqueología e Historia 15, 285-294.

Ramos Gil, M., 2016. Casas señoriales de Córdoba y otras casas principales. Córdoba.

Rodríguez Temiño, I., 2004. Arqueología urbana en España. Barcelona.

Ruiz Bueno, M.D., 2018. Dinámicas topográficas urbanas en Hispania. El espacio intramuros entre los siglos II y VII d.C.. Edipuglia, Bari.

Ruiz Rodríguez, A., Molinos Molinos, M., Rueda, C., Fernández, R., 20115. El palacio y el urbanismo del oppidum de Puente Tablas (Jaén). En: Ruiz Rodríguez, A., Molinero, M. (Eds.), Jaén, tierra ibera: 40 años de investigación y transferencia, 107-118. Jaén.
Salvatierra, V., 2013. En los adentros de la ciudad. Arqueología y urbanismo. En: Quirós, J.A., La materialidad de la historia. La arqueología en los inicios del siglo XXI, 241-270. Madrid.

Sánchez Ramos, I., Mateos, P. (Eds.), 2018. Territorio, topografía y arquitectura de poder durante La Antigüedad Tardía. CSIC-Junta de Extremadura - Instituto de Arqueología, Mérida. (Mytra 1).

Vallejo, A., 2010. La ciudad califal de Madinat al-Zahra. Arqueología de su excavación. Córdoba.

Vaquerizo, D., 2018 . Cuando (no siempre) hablan las piedras. Hacia una arqueología integral en España como recurso de futuro. Reflexiones desde Andalucía. JAS Arqueología, Madrid.

Vaquerizo, D., 2018b, Vivir en la Córdoba romana. En: Vaquerizo Gil, D. (Coord.), La historia de Córdoba a través de sus barrios (I). De los vici romanos a los arrabales islámicos, 33116. Córdoba.

Vaquerizo, D., Murillo, J.F. (Eds), 2010. El anfiteatro romano de Córdoba y su entorno urbano. Análisis arqueológico (ss. I-XIII d.C.). 2 vols. Córdoba. (MgAC 19).

Vaquerizo, D., Quesada, F., Murillo, J.F., 1994. Unidades de hábitat y técnicas constructivas en el yaci-miento ibérico del Cerro de la Cruz (Almedinilla, Córdoba). Anales de Arqueología Cordobesa 5, 61-98.

Vázquez Navajas, B., 2018. Vivir en la Córdoba islámica: la etapa califal. En: Vaquerizo Gil, D. (Coord.), La historia de Córdoba a través de sus barrios (I). De los vici romanos a los arrabales islámicos, 323-350. Córdoba.

Viana, I., 2013. Arqueología y Medios de Comunicación. En: Almansa, J. (Ed.), Arqueología Pública en España, 95-113. Madrid.

Vizcaíno, A. 2015. Dilemas, reflexiones y posibilidades de una investigación arqueológica que se pretende socialmente comprometida. La Linde 5, 193-214.

Zanker, P., 1998. Pompeii. Public and Prívate Life. Harvard University Press. 